\title{
Review Article \\ Exercise Prevention of Cardiovascular Disease in Breast Cancer Survivors
}

\author{
Amy A. Kirkham ${ }^{1}$ and Margot K. Davis ${ }^{2}$ \\ ${ }^{1}$ Rehabilitation Sciences, University of British Columbia, 212-2177 Wesbrook Mall, Vancouver, BC, Canada V6T 1Z3 \\ ${ }^{2}$ Division of Cardiology, University of British Columbia, Diamond Health Care Centre, 9th Floor, 2775 Laurel Street, \\ Vancouver, BC, Canada V5Z $1 M 9$ \\ Correspondence should be addressed to Margot K. Davis; margot.davis@ubc.ca
}

Received 5 September 2014; Accepted 11 December 2014

Academic Editor: Christine Brezden-Masley

Copyright (C) 2015 A. A. Kirkham and M. K. Davis. This is an open access article distributed under the Creative Commons Attribution License, which permits unrestricted use, distribution, and reproduction in any medium, provided the original work is properly cited.

\begin{abstract}
Thanks to increasingly effective treatment, breast cancer mortality rates have significantly declined over the past few decades. Following the increase in life expectancy of women diagnosed with breast cancer, it has been recognized that these women are at an elevated risk for cardiovascular disease due in part to the cardiotoxic side effects of treatment. This paper reviews evidence for the role of exercise in prevention of cardiovascular toxicity associated with chemotherapy used in breast cancer, and in modifying cardiovascular risk factors in breast cancer survivors. There is growing evidence indicating that the primary mechanism for this protective effect appears to be improved antioxidant capacity in the heart and vasculature and subsequent reduction of treatmentrelated oxidative stress in these structures. Further clinical research is needed to determine whether exercise is a feasible and effective nonpharmacological treatment to reduce cardiovascular morbidity and mortality in breast cancer survivors, to identify the cancer therapies for which it is effective, and to determine the optimal exercise dose. Safe and noninvasive measures that are sensitive to changes in cardiovascular function are required to answer these questions in patient populations. Cardiac strain, endothelial function, and cardiac biomarkers are suggested outcome measures for clinical research in this field.
\end{abstract}

\section{Introduction}

Breast cancer is the most common malignancy among women worldwide [1], and an estimated $1 \%$ of the population are survivors of breast cancer [2]. Advances in breast cancer therapy have contributed to dramatic improvements in survival, but many of these therapies, particularly anthracycline chemotherapy, left-sided radiotherapy, and trastuzumab targeted therapy, are associated with cardiovascular toxicities [3]. Breast cancer survivors are at increased risk of cardiovascular disease-related death compared to women without breast cancer [4], likely due in part to these toxicities. An increased prevalence of traditional cardiovascular risk factors in this population at diagnosis, and lifestyle perturbations associated with cancer treatment also contribute to this increased risk [3]. Chemotherapy for breast cancer will induce menopause in one- to two-thirds of women [5], further increasing cardiovascular risk $[1,6]$. As breast cancer survival rates rise, cardiovascular disease becomes an increasingly important competing risk [7]. Combined, these factors contribute to the recent finding that cardiovascular disease has surpassed breast cancer as the leading cause of death in older women diagnosed with breast cancer [8].

Current strategies to mitigate cardiotoxicity associated with anthracycline treatment include dose reduction, modified administration methods, liposomal formulations, and administration of cardioprotective medications [9]. However, dose modification may be associated with reduced oncological benefit [10], and pharmacological interventions may be associated with additional side effects.

Aerobic exercise training and other forms of physical activity are effective in primary and secondary prevention of cardiovascular disease and cardiovascular disease-related death [11]. For breast cancer survivors, exercise training is safe and effective in improving cardiorespiratory fitness, strength, body composition, fatigue, anxiety, depression, 
and quality of life, and is recommended during and after treatment [12]. However, the effect of aerobic exercise on cardiovascular function and outcomes during or after breast cancer treatment is not well established in humans.

The purpose of this paper is to (1) review the potential mechanisms mediating exercise prevention of cardiovascular toxicity; (2) review the available evidence for the role of exercise in prevention of cardiovascular disease in breast cancer survivors, including predominantly preclinical studies of the heart and clinical studies of cardiovascular risk factors; and (3) suggest outcome measures for translation of the preclinical findings to clinical studies.

\section{Potential Mechanisms Mediating Exercise Prevention of Cardiovascular Toxicity}

The vast majority of studies investigating exercise prevention of direct cardiovascular toxicity are in rodent models utilizing the anthracycline agent doxorubicin and compare an exercise-trained treated group to a sedentary treated group. The discussion of mechanisms and preclinical evidence refers to studies with this design unless otherwise noted. The mechanism underlying the cardioprotective effects of aerobic exercise before or during treatment with doxorubicin has not been fully elucidated but is likely to be multifactorial with summative effects and feedback from diverse processes. Potential mechanisms by which exercise may act in opposition to the negative effects of doxorubicin to protect the heart and vasculature are listed in Table 1 . There is available evidence for exercise protection mechanisms related to reduced oxidative stress, interruption of topoisomerasemediated pathways, cardiomyocyte contractile protein isoform shifts, and upregulation of heat shock proteins (HSP), endothelial nitric oxide (NO), and endothelial progenitor cells.

The most widely supported mechanism by which exercise may prevent doxorubicin cardiotoxicity is through its antioxidant effects. The production of reactive oxygen species (ROS) is one of the possible mechanisms for doxorubicin cardiotoxicity $[13,14]$. Although cells are equipped with an endogenous antioxidant system to protect against ROS, cardiomyocytes have only one fourth of the antioxidative capacity of the liver and other tissues [15], making them particularly vulnerable to oxidative stress. Exercise-induced enhancement of cardiomyocyte antioxidant capacity may prevent ROS-induced damage associated with doxorubicin treatment [16]. Compared with untrained animals, exercisetrained rodents have increased levels of antioxidant activity and reduced levels of oxidative stress markers following doxorubicin exposure [17-22]. However this mechanism may not play a role in cardioprotection when exercise is of low intensity and duration [23]. Reduced levels of protein turnover via the ubiquitin-proteasome pathway, an important mechanism for degradation of cellular proteins with oxidative damage, have been demonstrated in exercise-trained rodents compared to sedentary rodents [24]. This finding provides further support for exercise protection via reduced oxidative stress.
Anthracycline-induced ROS cause lipid peroxidation [25] and downregulate expression of the sarcoplasmic reticulum calcium pump, SERCA2a [14]. Decreased calcium uptake by SERCA2a then leads to an increase in cytosolic calcium [14]. These two changes result in opening of the mitochondrial permeability transition pore, allowing release of calcium from the mitochondrial matrix, downregulation of mitochondrial respiration, and leaking of proapoptotic mitochondrial proteins into the cytosol $[26,27]$. A single submaximal exercise session 24 hours before doxorubicin treatment prevented opening of the mitochondria permeability transition pore, mitigating the downstream effects [26]. This hypothesis is supported indirectly by several other studies demonstrating attenuation of doxorubicin-associated increases in the proapoptotic proteins caspase- 9 and 3 in exercise trained rodents $[18,23,24,26]$. These findings may be related to modulation of defense systems including stress chaperones like HSPs, or antioxidants, but may not be related to exerciseinduced upregulation of SERCA2a $[28,29]$.

There is emerging evidence implicating topoisomerase $2 \beta$, an enzyme regulating DNA unwinding, in doxorubicininduced cardiomyocyte mitochondrial dysfunction [30], secondary to downregulation of peroxisome proliferatoractivated receptor $-\gamma$ coactivator (PGC)- $1 \alpha$, a transcriptional coactivator of mitochondrial biogenesis [31]. Exercise training upregulates expression of PGC-1 $\alpha$ in skeletal muscle, although a similar response in cardiomyocytes has not been observed [32,33]. Two recent preclinical studies investigating the role of PGC- $1 \alpha$ in exercise cardioprotection did not demonstrate an interaction between exercise and doxorubicin [22, 34]. However, the capacity of exercise to impact topoisomerase $2 \beta$ and PGC- $1 \alpha$ in cardiomyocytes requires further investigation before this mechanism can be dismissed.

In the rodent heart, doxorubicin causes disruption of cardiac bioenergetics and an associated shift from the $\alpha$ isoform of the contractile protein, myosin heavy chain (MHC), to the $\beta$ isoform which has reduced contractile power [35]. Exercise training before $[28,35]$ and during doxorubicin treatment $[36,37]$ conserves the $\alpha$ isoform in rats. However, healthy human hearts express $7 \%$ of the $\alpha$ isoform on average, while this is the predominant isoform expressed in the rat heart [38]. Therefore the extent and subsequent impact of a doxorubicin-induced shift in MHC isoform distribution may be smaller for human myocardium. Clinical research is required to clarify the role of prevention of MHC isoform shifts in exercise cardioprotection.

HSPs control protein folding and unfolding, and are upregulated in cardiomyocytes during times of oxidative stress [24]. An exercise-induced increase in HSP expression is hypothesized to play a role in cardioprotection against doxorubicin by preserving the integrity and activity of mitochondrial respiratory complexes and thereby attenuating mitochondrial dysfunction [39]. Although there is some evidence supporting HSP-mediated cardioprotection [17, 19, $23]$, there are also conflicting results $[19,24,40]$.

Breast cancer therapies, including chemotherapy, targeted therapies, and radiotherapy, may be associated with endothelial dysfunction, a disease process involving impaired 
TABLE 1: Potential mechanisms for exercise prevention of doxorubicin-related cardiovascular toxicity.

\begin{tabular}{|c|c|c|c|c|}
\hline Myocardial target & Role of target & $\begin{array}{c}\text { Direction of } \\
\text { exercise-induced } \\
\text { change }^{*}\end{array}$ & $\begin{array}{c}\text { Direction of } \\
\text { doxorubicin-induced } \\
\text { change }^{*}\end{array}$ & $\begin{array}{l}\text { Evidence of exercise } \\
\text { prevention of } \\
\text { doxorubicin-induced } \\
\text { change }\end{array}$ \\
\hline \multicolumn{5}{|c|}{ Mechanisms with evidence for their role in exercise prevention } \\
\hline $\begin{array}{l}\text { Antioxidant to oxidative } \\
\text { stress ratio }\end{array}$ & $\begin{array}{l}\text { Prevention of oxidative } \\
\text { damage }\end{array}$ & $\uparrow[15]$ & $\downarrow[13]$ & $\begin{array}{l}\checkmark[17-21,52] \\
\times[23]\end{array}$ \\
\hline $\begin{array}{l}\text { Expression of } \alpha: \beta \text { myosin } \\
\text { heavy chain isoform in } \\
\text { rodents }\end{array}$ & $\begin{array}{l}\text { Motor protein required for } \\
\text { muscular contraction; in a } \\
\text { healthy rodent heart there } \\
\text { is a much higher } \\
\text { concentration of the } \alpha \\
\text { isoform }\end{array}$ & $\uparrow[154]$ & $\downarrow[155]$ & $\begin{array}{l}\checkmark[28,35-37] \\
\quad \times[23]\end{array}$ \\
\hline Caspase 3 and 9 activity & $\begin{array}{l}\text { Markers for apoptotic } \\
\text { signaling }\end{array}$ & $\downarrow[156]$ & $\uparrow[14]$ & $\checkmark[18,23,24,26]$ \\
\hline HSP 60 expression & $\begin{array}{l}\text { Controls protein folding } \\
\text { and unfolding in response } \\
\text { to stress }\end{array}$ & $\uparrow[18]$ & $\uparrow \uparrow[19]$ & $\checkmark[17,19]$ \\
\hline $\begin{array}{l}\text { Mitochondrial permeability } \\
\text { transition pore opening }\end{array}$ & $\begin{array}{l}\text { Regulation of calcium } \\
\text { handling and apoptosis }\end{array}$ & $\downarrow[157]$ & $\uparrow[158]$ & $\checkmark[26]$ \\
\hline $\begin{array}{l}\text { Ubiquitin-proteasome } \\
\text { activation }\end{array}$ & $\begin{array}{l}\text { Maintains protein function } \\
\text { and quality control }\end{array}$ & $\downarrow[159]$ & $\uparrow[160]$ & $\checkmark[24]$ \\
\hline $\begin{array}{l}\text { Endothelial progenitor cell } \\
\text { level }\end{array}$ & $\begin{array}{l}\text { Physiologic and pathologic } \\
\text { vessel formation }\end{array}$ & $\uparrow[54]$ & $\downarrow[161]$ & $\checkmark[55]$ \\
\hline HSP72 expression & $\begin{array}{l}\text { Controls protein folding } \\
\text { and unfolding in response } \\
\text { to stress }\end{array}$ & $\uparrow[18,162]$ & $=[163]$ & $\begin{aligned} & \checkmark[23] \\
\times & {[24,40] }\end{aligned}$ \\
\hline SERCA2a expression & $\begin{array}{l}\text { Calcium recycling from the } \\
\text { cytosol into the } \\
\text { sarcoplasmic reticulum }\end{array}$ & $\uparrow[164]$ & $\downarrow[165]$ & $\begin{array}{l}\checkmark[166] \\
\times[28,29]\end{array}$ \\
\hline \multicolumn{5}{|c|}{ Mechanisms with evidence against their role in exercise prevention } \\
\hline HSP 70 expression & $\begin{array}{l}\text { Controls protein folding } \\
\text { and unfolding in response } \\
\text { to stress }\end{array}$ & $\uparrow[167]$ & $\downarrow[168]$ & $\times[19]$ \\
\hline AMPK activation & $\begin{array}{l}\text { Senses and regulates energy } \\
\text { homeostasis }\end{array}$ & $\uparrow[169]$ & $\downarrow[170]$ & $\times[166]$ \\
\hline $\begin{array}{l}\text { Cardiac progenitor cell } \\
\text { level/heart mass }\end{array}$ & $\begin{array}{l}\text { Physiological turnover of } \\
\text { cardiomyocytes }\end{array}$ & $\uparrow[171]$ & $\downarrow[172]$ & $\times[29]$ \\
\hline Expression of PGC- $1 \alpha$ & $\begin{array}{l}\text { Transcription coactivator } \\
\text { that regulates } \\
\text { mitochondrial biogenesis } \\
\text { and angiogenesis }\end{array}$ & $=[32,33]$ & $\downarrow[173]$ & $\times[22,34]$ \\
\hline \multicolumn{5}{|c|}{ Potential mechanisms for exercise prevention lacking investigation } \\
\hline $\begin{array}{l}\text { Neuregulin-1/ErbB4 } \\
\text { signalling }\end{array}$ & $\begin{array}{l}\text { Cardiac cell survival } \\
\text { growth factor }\end{array}$ & $\uparrow[60]$ & $\downarrow[174]$ & $\emptyset$ \\
\hline Expression of GATA-4 & $\begin{array}{l}\text { Transcription factor } \\
\text { involved in cardiac } \\
\text { survival, hypertrophic } \\
\text { growth of the heart }\end{array}$ & $\uparrow[58]$ & $\downarrow[175]$ & $\emptyset$ \\
\hline
\end{tabular}

$\uparrow:$ increase; $\downarrow$ : decrease; =: no change; $\checkmark$ : evidence available in favor of this mechanism; $\times$ : evidence available against this mechanism; $\emptyset:$ no evidence available. HSP: heat shock protein; SERCA: sarcoplasmic reticulum calcium pump; AMPK: AMP-activated protein kinase; PGC: peroxisome proliferator-activated receptor- $\gamma$ coactivator.

* Note: Where possible reference cited provides evidence for the cardiomyocyte response, which may differ from other cell types. 
regulation of vascular tone and loss of atheroprotection [41]. Flow-mediated dilatation is triggered by shear stress from increased blood flow through a vessel, resulting in NO-mediated vasodilation [42]. Doxorubicin impairs both endothelium-dependent (i.e., flow-mediated) and endotheliumindependent vasodilation [41, 43, 44]. Breast radiation impairs endothelium-dependent vasodilation in exposed axillary arteries, causes ultrastructural damage to myocardial capillaries, and can induce atherosclerosis in coronary arteries [45-48]. Trastuzumab may cause endothelial dysfunction through reductions in NO [49].

Exercise training improves endothelial dysfunction, predominantly through increased NO production as a result of chronic periods of pulsatile blood flow [50]. In the presence of the superoxide ROS, NO reacts to form a reactive molecule that can damage DNA, and this reaction also decreases the bioavailability of NO [51]. The upregulation of antioxidative enzymes associated with exercise training may therefore promote NO bioavailability by scavenging ROS [51]. Hayward et al. provided evidence that exercise preconditioning prior to 5 -fluorouracil chemotherapy exposure increased NO production in rodents [52].

Endothelial progenitor cells (EPCs) contribute to maintaining the integrity of the endothelial cell layer, and lower levels of circulating EPCs are associated with an increased risk of cardiovascular events and death [53]. Exercise stimulates EPC mobilization from the bone marrow [54]. In human breast cancer survivors receiving doxorubicin-containing chemotherapy, exercise has been associated with an increase in circulating EPCs relative to usual care controls [55].

There are other proposed mechanisms for cardiotoxicity where exercise training could counteract the doxorubicininduced molecular response that have not yet been investigated as mechanisms for exercise cardioprotection. For example, pharmacological $\alpha 1$-adrenoceptor activation of the cardiac transcription factor GATA-4 has demonstrated cardioprotective capacity against doxorubicin [56]. Therefore, exercise training, which appears to enhance both $\alpha 1$-adrenoceptor responsiveness [57], and GATA-4 mRNA level in the heart [58] may also exert a cardioprotective effect via a GATA4 pathway. Another example includes doxorubicin and trastuzumab downregulation of neuregulin-1/ErbB4 receptor tyrosine kinase signaling in cardiomyocytes. Neuregulin1/ErbB4 signaling plays a critical role in cardiac development and cardiomyocyte survival and organization [59]. Intriguingly, exercise training upregulates expression of neuregulin1 in rodent cardiomyocytes [60], indicating a potential mechanism for exercise prevention of doxorubicin- and trastuzumab-related cardiotoxicity. Readers are referred to a more comprehensive review of potential mechanisms for exercise prevention of targeted cancer therapy-related cardiotoxicity [61].

In summary, although evidence exists for several different mechanisms through which exercise protects the heart and vasculature from doxorubicin-related toxicity, the unifying feature appears to be increased antioxidant capacity and reduction of oxidative stress. Several potential mechanisms, including exercise-induced upregulation of topoisomerase
$2 \beta /$ PGC-1 $\alpha$, GATA-4, and neuregulin-1/ErbB4 warrant further investigation to determine their role in cardioprotection.

\section{Evidence for Exercise Prevention of Cardiovascular Disease}

\subsection{Cardiotoxicity Prevention}

3.1.1. Acute Exercise. In animal models, doxorubicin-related cardiotoxicity can be attenuated by a single exercise session in close proximity to time of exposure. In the seminal study in this area, a 30-minute exercise session completed half an hour after doxorubicin exposure reduced mortality [62]. These findings were extended to demonstrate that an exhaustive exercise session half an hour after doxorubicin exposure attenuated markers of cardiomyocyte mitochondrial dysfunction [63]. Sixty minutes of submaximal exercise performed 24 hours prior to doxorubicin prevented or attenuated left ventricular (LV) systolic and diastolic dysfunction, cardiomyocyte mitochondrial apoptosis and dysfunction, and lipid peroxidation at 5 days post-treatment in rodents $[26,64]$.

The potential of a single exercise session to provide cardioprotection is particularly appealing, as regular, supervised exercise training during chemotherapy may not be feasible for all patients due to distance from home to exercise centers, difficulty with treatment symptoms, scheduling conflict with work, or family obligations. Ongoing research by our group is investigating the cardioprotective benefit of an acute exercise session 24 hours prior to doxorubicin administration in women with breast cancer.

3.1.2. Exercise Training before Treatment. In animals receiving high-dose bolus doxorubicin, exercise preconditioning prevents or attenuates acute ( 24 hour post) increases in cardiac troponin I $[17,18]$, markers of oxidative stress [17$21,24,65]$, cardiomyocyte mitochondrial dysfunction $[18,19$, 24], morphological and histological damage [16], markers of apoptosis [18, 24, 66], and decreases in HSP expression $[17,19]$ and LV systolic function [40, 65]. Similar findings have been reported in studies that extended the follow-up time to 5-10 days after doxorubicin exposure [35, 40, 67, 68]. Findings exclusive to studies with longer follow-up include attenuation of deficits in coronary flow [40], transmitral, and transaortic flow [35, 67], as well as transformation to the $\beta$-MHC isoform [35]. Even at four weeks after doxorubicin exposure, the beneficial effects of exercise preconditioning on $\beta$-MHC transformation, LV wall thickness, mass and systolic function, and transmitral/transaortic flow were still apparent [28].

The feasibility of exercise preconditioning in humans has been questioned, as the interval between breast cancer diagnosis and treatment is shorter than the length of most training programs that have been studied (8 to 14 weeks). However, cardioprotective effects have been reported after as little as 5 days to 3 weeks of training in rodents $[21,24,66]$. It should be noted that administered doxorubicin doses in these studies were higher than comparable human doses. It 
is unclear whether similar benefits would be seen in patients receiving standard treatment doses.

3.1.3. Exercise Training during Treatment. Exercise training concurrent to chronic doxorubicin treatment in rodents has been associated with attenuation of LV systolic and diastolic dysfunction $[23,29,37,69,70]$, cardiomyocyte apoptosis [23], transformation to $\beta$-MHC $[36,37]$, reductions in LV wall thickness [69] and heart mass [22], and deficits in coronary [23], transmitral, and transaortic flow [29, 37, 69].

Exercise training in humans during chemotherapy treatment for breast cancer is feasible and prevents the decrease in cardiorespiratory fitness seen in usual care controls [7072]. Preliminary clinical studies of the effects of exercise training on cardiac function in humans undergoing breast cancer treatment have had disappointing results, however. A small randomized control trial of exercise training compared to usual care during doxorubicin-containing chemotherapy for breast cancer found no change in LV ejection fraction (LVEF) in either group [70]. A single-arm study investigated the effects of four months of exercise training in 17 breast cancer survivors receiving adjuvant trastuzumab therapy. Despite exercise training, trastuzumab was associated with LV dilatation and reduced LVEF [73]. However the exercise training dose may have been insufficient, as participants did not attend $41 \%$ of exercise sessions. More sensitive measures of cardiac function and a higher exercise dose are likely required in order to demonstrate a cardioprotective benefit in clinical studies.

3.1.4. Exercise Training after Treatment. Although Héon et al. have reported reduced markers of cardiomyocyte apoptosis and oxidative stress in rodents undergoing exercise training two weeks after the completion of doxorubicin administration [74], to our knowledge the effects of post-treatment exercise on cardiac function have not been studied.

3.1.5. Summary of Cardiotoxicity Prevention Evidence. In summary, acute and chronic exercise before, during or after doxorubicin treatment in rodents consistently results in prevention or attenuation of doxorubicin-induced deleterious effects to cardiomyocyte morphology and biochemistry, as well as cardiac function. Preclinical experimental research is needed to determine whether exercise can provide cardioprotection from cancer therapies other than doxorubicin.

3.2. Vascular Toxicity Prevention. Few studies have investigated the effects of exercise on vascular function during breast cancer treatment. Six weeks of exercise training, initiated four weeks after doxorubicin treatment, was associated with improved endothelium-independent but not endotheliumdependent vasodilation, and with reduced mortality in rats with cardiac dysfunction [75]. Similarly, eight, but not four weeks of exercise training prior to exposure to 5 -fluorouracil chemotherapy was associated with enhanced endotheliumdependent vasodilation in rats [52]. In humans, two small randomized trials of the effect of exercise training during doxorubicin-containing chemotherapy on endothelial function have had conflicting results $[55,70]$. To advance understanding of exercise prevention of cardiovascular disease in breast cancer survivors, future exercise cardioprotection studies should include measurement of vascular function in addition to the cardiac measures.

\subsection{Cardiovascular Risk Factors Modification. Traditional} cardiovascular risk factors should be monitored and managed in breast cancer patients who receive cardiotoxic cancer therapies to prevent additional injury [76]. Exercise can favorably improve a number of cardiovascular risk factors including hypertension, raised cholesterol/lipids, overweight and obesity, raised blood glucose or diabetes, and cardiorespiratory fitness [77].

Hypertension is more than twice as prevalent among breast cancer survivors aged 55 and older as it is among the general population [78], and may be caused by chemotherapy agents used to treat breast cancer including cyclophosphamide, cisplatin and carboplatin [79]. Chemotherapy for breast cancer is also associated with elevations in triglyceride levels [80], while tamoxifen treatment may reduce levels of protective high density lipoprotein (HDL) [81]. Prior to treatment, breast cancer survivors may already have a suboptimal lipid profile including higher total cholesterol, triglyceride, and low density lipoprotein levels, and lower HDL levels than healthy controls [82-86]. A similar pattern occurs with overweight or obesity, where overweight, a risk factor for development of breast cancer [87], is often an issue prior to treatment, and chemotherapy treatment perpetuates the problem via its association with greater weight gains than other treatments in the year following diagnosis [88]. Therefore, it is not surprising that almost half of breast cancer survivors are overweight or obese [89]. Treatment also has lasting adverse effects on peak oxygen consumption $\left(\mathrm{VO}_{2}\right)$, the gold standard measurement of cardiorespiratory fitness [90]. Chemotherapy causes a 6-10\% reduction in peak $\mathrm{VO}_{2}[71,91]$, and following breast cancer treatment completion, remains an average of $22 \%$ lower than that of healthy sedentary controls [92]. Furthermore, the level of cardiorespiratory fitness amongst breast cancer survivors appears to mediate incidence of cardiovascular disease and risk factors [93]. Lastly, breast cancer survivors are at an increased risk for diabetes from two up to 10 years following diagnosis [94], and its presence increases the risk of mortality in this population [95]. In early stage breast cancer survivors, high blood insulin levels, indicative of insulin resistance, are associated with obesity, poor lipid profiles [96], distant recurrence and death [97].

A number of exercise intervention studies in human breast cancer survivors have included cardiovascular risk factors as outcome measures. Exercise interventions in breast cancer survivors have consistently reported decreases in systolic blood pressure of 3-5 $\mathrm{mmHg}$ both during [98-100] and after $[99,101-105]$ treatment. Reported effects on blood lipids following an exercise intervention with or without dietary intervention include significant positive effects on triglycerides [102, 105], and HDL [105], or no effect [104, 106, 
107]. Numerous exercise interventions have measured weight or body composition change with mixed results, showing either no effect or weight reduction [12]. Small feasibility studies have demonstrated that the combination of exercise with a diet intervention could be more effective in reducing weight in breast cancer survivors [106, 107]. Exercise training during chemotherapy or radiation treatment for breast cancer at minimum can prevent the peak $\mathrm{VO}_{2}$ decline occurring in usual care controls [71], or improve peak $\mathrm{VO}_{2}$ [70, 72, 91, 108, 109]. Exercise training following completion of breast cancer treatment improves peak $\mathrm{VO}_{2}[106,110,111]$. Only one [105] of six randomized controlled trials to examine the effect of an exercise intervention on insulin and/or insulin resistance demonstrated statistically significant changes $[104,107,112-$ 114]. This same study also reported improvements in fasting blood glucose [105].

In summary, exercise interventions appear to have clinically meaningful effects on blood pressure and peak $\mathrm{VO}_{2}$, whereas the effects on blood lipids, weight, and insulin/ glucose and potential development of diabetes are less clear. The strong established relationships between both blood pressure and peak $\mathrm{VO}_{2}$ and cardiovascular disease development and mortality in noncancer populations [6, 115117] provide convincing support for the role of exercise in prevention of cardiovascular disease in human breast cancer survivors.

\section{Translation of Preclinical Findings to Clinical Studies}

Substantial preclinical evidence supports the role of exercise in prevention of cardiovascular disease toxicity, and there is some evidence for modification of cardiovascular risk factors in clinical trials. Further clinical research is warranted to determine whether exercise is a feasible and effective method for the reduction of cardiovascular morbidity and mortality in breast cancer survivors. Barriers to the translation of preclinical findings to human models include the need for more sensitive outcome measures and uncertainty regarding the optimal exercise dose.

Demonstration of the cardioprotective benefits of exercise in rodents has typically required euthanasia. One of the greatest barriers to this research in humans is identification of a noninvasive and sensitive outcome measure. Threedimensional echocardiography-derived LVEF has emerged as a more reliable measure of LV function in patients receiving chemotherapy compared to traditional twodimensional imaging [118], although this does not necessarily imply greater sensitivity to early changes in function. Echocardiography-derived LV global longitudinal strain and strain rate are able to detect changes in cardiac function during chemotherapy, radiation and trastuzumab treatment before changes in LVEF are detectable [119]. In noncancer populations, cardiac strain responds to exercise training [120]. Our research group is conducting an ongoing study to determine whether exercise training can prevent the doxorubicin-related decline in cardiac strain parameters in women with breast cancer. These parameters are widely available in conjunction with standard echocardiography [121]; with acceptable inter- and intra-observer variability (5\% and 3.5\%, resp.) [122]. Global longitudinal strain is predictive of all-cause mortality for a number of other cardiac conditions [123-126], and may be a stronger predictor of outcomes than LVEF $[123,126]$, but its relationship with clinical outcomes other than LVEF in breast cancer survivors is unknown.

Endothelial function is another attractive clinical outcome measure because dysfunction is an early process in the development of cardiovascular disease, and in noncancer populations, responds to pharmacological $[42,127]$ and exercise [50] interventions. Endothelial function can be easily measured in humans with a reactive hyperemia test, in which a cuff is inflated around the arm to occlude blood flow for 5 minutes. With release, the sudden increase in blood flow causes vasodilatation, which can be measured with ultrasound or peripheral arterial tonometry [127].

Cardiac biomarkers may play a role in predicting and identifying cardiotoxicity [128]. N-terminal prohormone brain natriuretic peptide (NT-proBNP) is frequently elevated during and after anthracycline treatment in adults [129131]. There is mixed evidence regarding its ability to predict cardiac dysfunction following anthracycline treatment [130132], as several studies where trastuzumab treatment followed anthracycline treatment, do not report a predictive ability of NT-proBNP [122, 133-135]. Due to inter-individual variations in kinetics, several measurements may be required to capture an elevation in cardiac troponins in patients receiving anthracyclines $[122,129,130,133,134,136-146]$, but the occurrence of an elevation in troponin I is predictive of chemotherapy and trastuzumab-related decreases in LVEF $[139,147]$, and cardiac events [140]. Exercise in heart failure patients does not change levels of NT-proBNP [148] or cardiac troponin I [149], but chronic heart failure has a different pathophysiology than the acute effects of cardiotoxic cancer therapies. Nonetheless, cardiac biomarkers may prove to be an effective outcome measure for exercise cardioprotection interventions due to their accessibility and reliability as a marker of cardiotoxicity.

Another important factor in the effective translation of preclinical findings to humans is the exercise intervention design. While preclinical and clinical experimental studies demonstrate that high intensity aerobic exercise results in greater cardiac benefits than moderate or low intensity [150, 151], the strenuous exercise prescription applied in most preclinical studies (five days a week, moderate to high intensity, 20-90 minutes) would likely not be tolerable for humans undergoing chemotherapy treatment [152]. One rodent study implemented a more clinically feasible and practical exercise prescription and doxorubicin treatment protocol involving 20 minutes of low intensity exercise, performed five days per week during chronic low dose doxorubicin treatment [23]. Although the lower doxorubicin dose failed to induce the MHC isoform shift and lipid peroxidation reported with higher doses, the lower exercise dose was protective against LV dysfunction and cardiomyocyte apoptosis [23]. In heart failure patients, moderate intensity exercise performed three days per week has been shown to improve systolic function [153]. Therefore, the required exercise dose for 
cardioprotection likely involves three to five days per week of moderate to high intensity aerobic exercise of at least 20 minutes in duration, but greater benefits will likely occur with higher doses. The optimal prescription requires a balance of patient tolerance with protective efficacy.

\section{Conclusion}

Breast cancer therapy has efficacious antitumor effects, but is associated with increased risk of cardiovascular disease. A considerable body of research, including preclinical studies and clinical trials, indicates that exercise may be an effective nonpharmacological method of attenuating the harmful effects of breast cancer therapies on the heart and vasculature, of modifying cardiovascular risk factors, and potentially reducing cardiovascular morbidity and mortality in this vulnerable population. The mechanisms for exercise prevention appear to be predominantly related to an increase in antioxidant capacity and associated reduction in oxidative stress. Clinical trials are needed to investigate the role of exercise in the prevention of direct cardiovascular toxicity of breast cancer treatment and the effect on cardiovascular events and mortality. The role of exercise in the prevention of cardiovascular disease in other cancer populations also warrants further research, as the detrimental combination of a high incidence of baseline risk factors combined with cancer treatment cardiovascular toxicity may be common to multiple cancer types. Echocardiographic quantification of LV global longitudinal strain and strain rate, endothelial function quantification, and measurement of circulating cardiac biomarkers are safe, noninvasive measures that may be sensitive and effective outcome measures for clinical studies of exercise prevention of breast cancer treatment-related cardiovascular toxicity. The exercise frequency, intensity, and duration demonstrating cardioprotection in most preclinical studies may need to be modified to accommodate human patient tolerability during ongoing cancer treatment.

\section{Conflict of Interests}

The authors declare that there is no conflict of interests regarding the publication of this paper.

\section{Acknowledgments}

Amy Kirkham is supported by a Canada Graduate Scholarship from the Canadian Institute of Health Research. Margot Davis is supported by a Vancouver Coastal Health Research Institute Mentored Clinician Scientist award.

\section{References}

[1] P. Boyle and B. Levin, Eds., World Cancer Report, International Agency for Research on Cancer, Lyon, France, 2008.

[2] Canadian Cancer Society/National Cancer Institute of Canada, Canadian cancer statistics 2007, Canadian Cancer Society/ National Cancer Institute of Canada, Toronto, Canada, 2007.

[3] L. W. Jones, M. J. Haykowsky, J. J. Swartz, P. S. Douglas, and J. R. Mackey, "Early breast cancer therapy and cardiovascular injury,"
Journal of the American College of Cardiology, vol. 50, no. 15, pp. 1435-1441, 2007.

[4] M. Riihimäki, H. Thomsen, A. Brandt, J. Sundquist, and K. Hemminki, "Death causes in breast cancer patients," Annals of Oncology, vol. 23, no. 3, pp. 604-610, 2012.

[5] S. E. Minton and P. N. Munster, "Chemotherapy-induced amenorrhea and fertility in women undergoing adjuvant treatment for breast cancer," Cancer Control, vol. 9, no. 6, pp. 466-472, 2002.

[6] World Heart Federation, Cardiovascular Disease Risk Factors, World Heart Federation, Geneva, Switzerland, 2013.

[7] M. S. Ewer and S. Glück, "A woman's heart: the impact of adjuvant endocrine therapy on cardiovascular health," Cancer, vol. 115, no. 9, pp. 1813-1826, 2009.

[8] J. L. Patnaik, T. Byers, C. DiGuiseppi, D. Dabelea, and T. D. Denberg, "Cardiovascular disease competes with breast cancer as the leading cause of death for older females diagnosed with breast cancer: a retrospective cohort study," Breast Cancer Research, vol. 13, no. 3, article R64, 2011.

[9] A. R. Lehenbauer Ludke, A. A.-R. S. Al-Shudiefat, S. Dhingra, D. S. Jassal, and P. K. Singal, "A concise description of cardioprotective strategies in doxorubicin-induced cardiotoxicity," Canadian Journal of Physiology and Pharmacology, vol. 87, no. 10, pp. 756-763, 2009.

[10] J. Chang, "Chemotherapy dose reduction and delay in clinical practiceevaluating the risk to patient outcome in adjuvant chemotherapy for breast cancer," European Journal of Cancer, vol. 36, no. 1, pp. 11-14, 2000.

[11] D. E. R. Warburton, C. W. Nicol, and S. S. D. Bredin, "Health benefits of physical activity: the evidence," Canadian Medical Association Journal, vol. 174, no. 6, pp. 801-809, 2006.

[12] K. H. Schmitz, K. S. Courneya, C. Matthews et al., "American college of sports medicine roundtable on exercise guidelines for cancer survivors," Medicine and Science in Sports and Exercise, vol. 42, no. 7, pp. 1409-1426, 2010.

[13] D. A. Gewirtz, "A critical evaluation of the mechanisms of action proposed for the antitumor effects of the anthracycline antibiotics adriamycin and daunorubicin," Biochemical Pharmacology, vol. 57, no. 7, pp. 727-741, 1999.

[14] G. Minotti, P. Menna, E. Salvatorelli, G. Cairo, and L. Gianni, "Anthracyclines: molecular advances and pharmacologie developments in antitumor activity and cardiotoxicity," Pharmacological Reviews, vol. 56, no. 2, pp. 185-229, 2004.

[15] K. Husain and S. M. Somani, "Response of cardiac antioxidant system to alcohol and exercise training in the rat," Alcohol, vol. 14, no. 3, pp. 301-307, 1997.

[16] A. Ascensão, J. Magalhães, J. Soares et al., "Endurance exercise training attenuates morphological signs of cardiac muscle damage induced by doxorubicin in male mice," Basic and Applied Myology, vol. 16, pp. 27-35, 2006.

[17] A. Ascensão, J. Magalhães, J. Soares et al., "Endurance training attenuates doxorubicin-induced cardiac oxidative damage in mice," International Journal of Cardiology, vol. 100, no. 3, pp. 451-460, 2005.

[18] A. Ascensão, J. Magalhães, J. M. C. Soares et al., "Moderate endurance training prevents doxorubicin-induced in vivo mitochondriopathy and reduces the development of cardiac apoptosis," American Journal of Physiology-Heart and Circulatory Physiology, vol. 289, no. 2, pp. H722-H731, 2005.

[19] A. Ascensão, R. Ferreira, P. J. Oliveira, and J. Magalhães, "Effects of endurance training and acute doxorubicin treatment on rat 
heart mitochondrial alterations induced by in vitro anoxiareoxygenation," Cardiovascular Toxicology, vol. 6, no. 3-4, pp. 159-172, 2006.

[20] J. Ashrafi, V. D. Roshan, and S. Mahjoub, "Cardioprotective effects of aerobic regular exercise against doxorubicin-induced oxidative stress in rat," African Journal of Pharmacy and Pharmacology, vol. 6, pp. 2380-2388, 2012.

[21] J. Ashrafi and V. D. Roshan, "Is short-term exercise a therapeutic tool for improvement of cardioprotection against DOX-induced cardiotoxicity? An experimental controlled protocol in rats," Asian Pacific Journal of Cancer Prevention, vol. 13, no. 8, pp. 4025-4030, 2012.

[22] I. Marques-Aleixo, E. Santos-Alves, D. Mariani et al., "Physical exercise prior and during treatment reduces sub-chronic doxorubicin-induced mitochondrial toxicity and oxidative stress," Mitochondrion, vol. 20, pp. 22-33, 2015.

[23] A. J. Chicco, D. S. Hydock, C. M. Schneider, and R. Hayward, "Low-intensity exercise training during doxorubicin treatment protects against cardiotoxicity," Journal of Applied Physiology, vol. 100, no. 2, pp. 519-527, 2006.

[24] A. N. Kavazis, A. J. Smuder, K. Min, N. Tümer, and S. K. Powers, "Short-term exercise training protects against doxorubicininduced cardiac mitochondrial damage independent of HSP72," American Journal of Physiology-Heart and Circulatory Physiology, vol. 299, no. 5, pp. H1515-H1524, 2010.

[25] C. A. Geisberg and D. B. Sawyer, "Mechanisms of anthracycline cardiotoxicity and strategies to decrease cardiac damage," Current Hypertension Reports, vol. 12, no. 6, pp. 404-410, 2010.

[26] A. Ascensão, J. Lumini-Oliveira, N. G. Machado et al., "Acute exercise protects against calcium-induced cardiac mitochondrial permeability transition pore opening in doxorubicintreated rats," Clinical Science, vol. 120, no. 1, pp. 37-49, 2011.

[27] M. R. Duchen, "Mitochondria and calcium: from cell signalling to cell death," Journal of Physiology, vol. 529, no. 1, pp. 57-68, 2000 .

[28] D. S. Hydock, C.-Y. Lien, B. T. Jensen, C. M. Schneider, and R. Hayward, "Exercise preconditioning provides long-term protection against early chronic doxorubicin cardiotoxicity," Integrative Cancer Therapies, vol. 10, no. 1, pp. 47-57, 2011.

[29] R. Hayward, C.-Y. Lien, B. T. Jensen, D. S. Hydock, and C. M. Schneider, "Exercise training mitigates anthracycline-induced chronic cardiotoxicity in a juvenile rat model," Pediatric Blood and Cancer, vol. 59, no. 1, pp. 149-154, 2012.

[30] S. Zhang, X. Liu, T. Bawa-Khalfe et al., "Identification of the molecular basis of doxorubicin-induced cardiotoxicity," Nature Medicine, vol. 18, no. 11, pp. 1639-1642, 2012.

[31] P. Vejpongsa and E. T. H. Yeh, “Topoisomerase $2 \beta$ : a promising molecular target for primary prevention of anthracyclineinduced cardiotoxicity," Clinical Pharmacology \& Therapeutics, vol. 95, no. 1, pp. 45-52, 2014.

[32] A. Botta, I. Laher, J. Beam et al., "Short term exercise induces PGC- $1 \alpha$, ameliorates inflammation and increases mitochondrial membrane proteins but fails to increase respiratory enzymes in aging diabetic hearts," PLoS ONE, vol. 8, no. 8, Article ID e70248, 2013.

[33] L. Li, C. Mühlfeld, B. Niemann et al., "Mitochondrial biogenesis and PGC-1 $\alpha$ deacetylation by chronic treadmill exercise: differential response in cardiac and skeletal muscle," Basic Research in Cardiology, vol. 106, no. 6, pp. 1221-1234, 2011.
[34] A. N. Kavazis, A. J. Smuder, and S. K. Powers, "Effects of short-term endurance exercise training on acute doxorubicininduced FoxO transcription in cardiac and skeletal muscle," Journal of Applied Physiology, vol. 117, no. 3, pp. 223-230, 2014.

[35] D. S. Hydock, C.-Y. Lien, C. M. Schneider, and R. Hayward, "Exercise preconditioning protects against doxorubicin-induced cardiac dysfunction," Medicine and Science in Sports and Exercise, vol. 40, no. 5, pp. 808-817, 2008.

[36] D. S. Hydock, K. Y. Wonders, C. M. Schneider, and R. Hayward, "Voluntary wheel running in rats receiving doxorubicin: effects on running activity and cardiac myosin heavy chain," Anticancer Research, vol. 29, no. 11, pp. 4401-4407, 2009.

[37] D. S. Hydock, C.-Y. Lien, B. T. Jensen, T. L. Parry, C. M. Schneider, and R. Hayward, "Rehabilitative exercise in a rat model of doxorubicin cardiotoxicity," Experimental Biology and Medicine, vol. 237, no. 12, pp. 1483-1492, 2012.

[38] S. Miyata, W. Minobe, M. R. Bristow, and L. A. Leinwand, "Myosin heavy chain isoform expression in the failing and nonfailing human heart," Circulation Research, vol. 86, no. 4, pp. 386-390, 2000.

[39] A. Ascensão, R. Ferreira, and J. Magalhães, "Exercise-induced cardioprotection-biochemical, morphological and functional evidence in whole tissue and isolated mitochondria," International Journal of Cardiology, vol. 117, no. 1, pp. 16-30, 2007.

[40] A. J. Chicco, C. M. Schneider, and R. Hayward, "Exercise training attenuates acute doxorubicin-induced cardiac dysfunction," Journal of Cardiovascular Pharmacology, vol. 47, no. 2, pp. 182189, 2006.

[41] J. T. Kuvin, A. R. Patel, K. A. Sliney et al., "Assessment of peripheral vascular endothelial function with finger arterial pulse wave amplitude," American Heart Journal, vol. 146, no. 1, pp. 168-174, 2003.

[42] M. Kelm, "Flow-mediated dilatation in human circulation: diagnostic and therapeutic aspects," The American Journal of Physiology - Heart and Circulatory Physiology, vol. 282, no. 1, pp. H1-H5, 2002.

[43] R. Hayward, D. Hydock, N. Gibson, S. Greufe, E. Bredahl, and T. Parry, "Tissue retention of doxorubicin and its effects on cardiac, smooth, and skeletal muscle function," Journal of Physiology and Biochemistry, vol. 69, no. 2, pp. 177-187, 2013.

[44] D. S. Celermajer, "Reliable endothelial function testing: at our fingertips?" Circulation, vol. 117, no. 19, pp. 2428-2430, 2008.

[45] J. A. Beckman, A. Thakore, B. H. Kalinowski, J. R. Harris, and M. A. Creager, "Radiation therapy impairs endotheliumdependent vasodilation in humans," Journal of the American College of Cardiology, vol. 37, no. 3, pp. 761-765, 2001.

[46] B. W. Corn, B. J. Trock, and R. L. Goodman, "Irradiation-related ischemic heart disease," Journal of Clinical Oncology, vol. 8, no. 4, pp. 741-750, 1990.

[47] A. M. Gaya and R. F. U. Ashford, "Cardiac complications of radiation therapy," Clinical Oncology, vol. 17, no. 3, pp. 153-159, 2005.

[48] R. Virmani, A. Farb, A. J. Carter, and R. M. Jones, "Pathology of radiation-induced coronary artery disease in human and pig," Cardiovascular Radiation Medicine, vol. 1, no. 1, pp. 98-101, 1999.

[49] A. Sandoo, G. D. Kitas, and A. R. Carmichael, "Endothelial dysfunction as a determinant of trastuzumab-mediated cardiotoxicity in patients with breast cancer," Anticancer Research, vol. 34, no. 3, pp. 1147-1151, 2014.

[50] D. J. Green, A. Spence, J. R. Halliwill, N. T. Cable, and D. H. J. Thijssen, "Exercise and vascular adaptation in asymptomatic humans," Experimental Physiology, vol. 96, no. 2, pp. 57-70, 2011. 
[51] S. Gielen, G. Schuler, and V. Adams, "Cardiovascular effects of exercise training: molecular mechanisms," Circulation, vol. 122, no. 12, pp. 1221-1238, 2010.

[52] R. Hayward, R. Ruangthai, C. M. Schneider, R. M. Hyslop, R. Strange, and K. C. Westerlind, "Training enhances vascular relaxation after chemotherapy-induced vasoconstriction," Medicine \& Science in Sports \& Exercise, vol. 36, no. 3, pp. 428-434, 2004.

[53] N. Werner, S. Kosiol, T. Schiegl et al., "Circulating endothelial progenitor cells and cardiovascular outcomes," The New England Journal of Medicine, vol. 353, no. 10, pp. 999-1007, 2005.

[54] U. Laufs, A. Urhausen, N. Werner et al., "Running exercise of different duration and intensity: effect on endothelial progenitor cells in healthy subjects," European Journal of Cardiovascular Prevention and Rehabilitation, vol. 12, no. 4, pp. 407-414, 2005.

[55] L. W. Jones, D. R. Fels, M. West et al., "Modulation of circulating angiogenic factors and tumor biology by aerobic training in breast cancer patients receiving neoadjuvant chemotherapy," Cancer Prevention Research, vol. 6, no. 9, pp. 925-937, 2013.

[56] A. Aries, P. Paradis, C. Lefebvre, R. J. Schwartz, and M. Nemer, "Essential role of GATA-4 in cell survival and drug-induced cardiotoxicity," Proceedings of the National Academy of Sciences of the United States of America, vol. 101, no. 18, pp. 6975-6980, 2004.

[57] D. H. Korzick and R. L. Moore, "Chronic exercise enhances cardiac $\alpha 1$-adrenergic inotropic responsiveness in rats with mild hypertension," American Journal of Physiology-Heart and Circulatory Physiology, vol. 271, no. 6, pp. H2599-H2608, 1996.

[58] J. Xiao, T. Xu, J. Li et al., "Exercise-induced physiological hypertrophy initiates activation of cardiac progenitor cells," International Journal of Clinical and Experimental Pathology, vol. 7, pp. 663-669, 2014.

[59] D. B. Sawyer, X. Peng, B. Chen, L. Pentassuglia, and C. C. Lim, "Mechanisms of anthracycline cardiac injury: can we identify strategies for cardioprotection?" Progress in Cardiovascular Diseases, vol. 53, no. 2, pp. 105-113, 2010.

[60] C. D. Waring, C. Vicinanza, A. Papalamprou et al., "The adult heart responds to increased workload with physiologic hypertrophy, cardiac stem cell activation, and new myocyte formation," European Heart Journal, vol. 35, no. 39, pp. 2722-2731, 2014.

[61] J. M. Scott, S. Lakoski, J. R. Mackey, P. S. Douglas, M. J. Haykowsky, and L. W. Jones, "The potential role of aerobic exercise to modulate cardiotoxicity of molecularly targeted cancer therapeutics," Oncologist, vol. 18, no. 2, pp. 221-231, 2013.

[62] A. B. Combs, S. L. Hudman, and H. W. Bonner, "Effect of exercise stress upon the acute toxicity of adriamycin in mice," Research Communications in Chemical Pathology and Pharmacology, vol. 23, no. 2, pp. 395-398, 1979.

[63] E. W. Mitchell, "Effects of adriamycin on heart mitochondrial function in rested and exercised rats," Biochemical Pharmacology, vol. 47, no. 5, pp. 877-885, 1994.

[64] K. Y. Wonders, D. S. Hydock, C. M. Schneider, and R. Hayward, "Acute exercise protects against doxorubicin cardiotoxicity," Integrative Cancer Therapies, vol. 7, no. 3, pp. 147-154, 2008.

[65] A. J. Chicco, C. M. Schneider, and R. Hayward, "Voluntary exercise protects against acute doxorubicin cardiotoxicity in the isolated perfused rat heart," American Journal of PhysiologyRegulatory Integrative and Comparative Physiology, vol. 289, no. 2, pp. R424-R431, 2005.

[66] C. Werner, M. Hanhoun, T. Widmann et al., "Effects of physical exercise on myocardial telomere-regulating proteins, survival pathways, and apoptosis," Journal of the American College of Cardiology, vol. 52, no. 6, pp. 470-482, 2008.

[67] B. T. Jensen, The effect of exercise on cardiac function and doxorubicin accumulation in left ventricular tissue of rats [Ph.D. dissertation], University of Northern Colorado, Greeley, Colo, USA, 2011.

[68] K. Y. Wonders, D. S. Hydock, S. Greufe, C. M. Schneider, and R. Hayward, "Endurance exercise training preserves cardiac function in rats receiving doxorubicin and the HER-2 inhibitor GW2974," Cancer Chemotherapy and Pharmacology, vol. 64, no. 6, pp. 1105-1113, 2009.

[69] D. S. Hydock, T. L. Parry, B. T. Jensen, C.-Y. Lien, C. M. Schneider, and R. Hayward, "Effects of endurance training on combined goserelin acetate and doxorubicin treatment-induced cardiac dysfunction," Cancer Chemotherapy and Pharmacology, vol. 68, no. 3, pp. 685-692, 2011.

[70] L. Jones, V. Dolinsky, M. Haykowsky et al., "Effects of aerobic training to improve cardiovascular function and prevent cardiac remodeling after cytotoxic therapy in early breast cancer," in Proceedings of the American Association for Cancer Research 102nd Annual Meeting, Orlando, Fla, USA, April 2011, abstract 5024.

[71] K. S. Courneya, R. J. Segal, J. R. Mackey et al., "Effects of aerobic and resistance exercise in breast cancer patients receiving adjuvant chemotherapy: a multicenter randomized controlled trial," Journal of Clinical Oncology, vol. 25, no. 28, pp. 43964404, 2007.

[72] A. L. Schwartz, K. Winters-Stone, and B. Gallucci, "Exercise effects on bone mineral density in women with breast cancer receiving adjuvant chemotherapy," Oncology Nursing Forum, vol. 34, no. 3, pp. 627-633, 2007.

[73] M. J. Haykowsky, J. R. Mackey, R. B. Thompson, L. W. Jones, and D. I. Paterson, "Adjuvant trastuzumab induces ventricular remodeling despite aerobic exercise training," Clinical Cancer Research, vol. 15, no. 15, pp. 4963-4967, 2009.

[74] S. Héon, M. Bernier, N. Servant et al., "Dexrazoxane does not protect against doxorubicin-induced damage in young rats," American Journal of Physiology-Heart and Circulatory Physiology, vol. 285, no. 2, pp. H499-H506, 2003.

[75] C. Matsuura, T. M. C. Brunini, L. C. M. M. Carvalho et al., "Exercise training in doxorubicin-induced heart failure: effects on the L-arginine-NO pathway and vascular reactivity," Journal of the American Society of Hypertension, vol. 4, no. 1, pp. 7-13, 2010.

[76] M. M. Abu-Khalaf and L. Harris, "Anthracycline-induced cardiotoxicity: risk assessment and management," Oncology, vol. 23, no. 3, pp. 239-252, 2009.

[77] G. F. Fletcher, G. Balady, S. N. Blair et al., "Statement on exercise: benefits and recommendations for physical activity programs for all Americans: a statement for health professionals by the committee on exercise and cardiac rehabilitation of the Council on Clinical Cardiology, American Heart Association," Circulation, vol. 94, no. 4, pp. 857-862, 1996.

[78] R. Yancik, R. J. Havlik, M. N. Wesley et al., "Cancer and comorbidity in older patients: a descriptive profile," Annals of Epidemiology, vol. 6, no. 5, pp. 399-412, 1996.

[79] E. Mouhayar and A. Salahudeen, "Hypertension in cancer patients," Texas Heart Institute Journal, vol. 38, no. 3, pp. 263265,2011

[80] C. G. Alexopoulos, S. Pournaras, M. Vaslamatzis, A. Avgerinos, and S. Raptis, "Changes in serum lipids and lipoproteins in 
cancer patients during chemotherapy," Cancer Chemotherapy and Pharmacology, vol. 30, no. 5, pp. 412-416, 1992.

[81] R. R. Love, D. A. Wiebe, P. A. Newcomb et al., "Effects of tamoxifen on cardiovascular risk factors in postmenopausal women," Annals of Internal Medicine, vol. 115, no. 11, pp. 860864, 1991.

[82] W. Thompat, S. Sukarayodhin, A. Sornprom, Y. Sudjaroen, and P. Laisupasin, "Comparison of serum lipid profiles between normal controls and breast cancer patients," Journal of Laboratory Physicians, vol. 5, no. 1, p. 38, 2013.

[83] K. Hasija and H. K. Bagga, "Alterations of serum cholesterol and serum lipoprotein in breast cancer of women," Indian Journal of Clinical Biochemistry, vol. 20, no. 1, pp. 61-66, 2005.

[84] E. Kökoğlu, I. Karaarslan, H. Mehmet Karaarslan, and H. Baloğlu, "Alterations of serum lipids and lipoproteins in breast cancer," Cancer Letters, vol. 82, no. 2, pp. 175-178, 1994.

[85] J.-B. Lopez-Saez, J. A. Martinez-Rubio, M. M. Alvarez et al., "Metabolic profile of breast cancer in a population of women in southern Spain," Open Clinical Cancer Journal, vol. 2, pp. 1-6, 2008.

[86] N. K. Yadav, B. Poudel, C. Thanpari, and B. C. Koner, "Assessment of biochemical profiles in premenopausal and postmenopausal women with breast cancer," Asian Pacific Journal of Cancer Prevention, vol. 13, no. 7, pp. 3385-3388, 2012.

[87] A. R. Carmichael and T. Bates, "Obesity and breast cancer: a review of the literature," Breast, vol. 13, no. 2, pp. 85-92, 2004.

[88] P. J. Goodwin, M. Ennis, K. I. Pritchard et al., "Adjuvant treatment and onset of menopause predict weight gain after breast cancer diagnosis," Journal of Clinical Oncology, vol. 17, no. 1, pp. 120-129, 1999.

[89] K. S. Courneya, P. T. Katzmarzyk, and E. Bacon, "Physical activity and obesity in Canadian cancer survivors: population-based estimates from the 2005 Canadian Community Health Survey," Cancer, vol. 112, no. 11, pp. 2475-2482, 2008.

[90] L. W. Jones, N. D. Eves, M. Haykowsky, S. J. Freedland, and J. R. Mackey, "Exercise intolerance in cancer and the role of exercise therapy to reverse dysfunction," The Lancet Oncology, vol. 10, no. 6, pp. 598-605, 2009.

[91] S. G. Lakoski, N. D. Eves, P. S. Douglas, and L. W. Jones, "Exercise rehabilitation in patients with cancer," Nature Reviews Clinical Oncology, vol. 9, no. 5, pp. 288-296, 2012.

[92] L. W. Jones, K. S. Courneya, J. R. Mackey et al., "Cardiopulmonary function and age-related decline across the breast cancer: survivorship continuum," Journal of Clinical Oncology, vol. 30, no. 20, pp. 2530-2537, 2012.

[93] J. B. Peel, X. Sui, S. A. Adams, J. R. HIbert, J. W. Hardin, and S. N. Blair, "A prospective study of cardiorespiratory fitness and breast cancer mortality," Medicine and Science in Sports and Exercise, vol. 41, no. 4, pp. 742-748, 2009.

[94] L. L. Lipscombe, W. W. Chan, L. Yun, P. C. Austin, G. M. Anderson, and P. A. Rochon, "Incidence of diabetes among postmenopausal breast cancer survivors," Diabetologia, vol. 56, no. 3, pp. 476-483, 2013.

[95] R. Yancik, M. N. Wesley, L. A. G. Ries, R. J. Havlik, B. K. Edwards, and J. W. Yates, "Effect of age and comorbidity in postmenopausal breast cancer patients aged 55 years and older," Journal of the American Medical Association, vol. 285, no. 7, pp. 885-892, 2001.

[96] P. J. Goodwin, M. Ennis, M. Bahl et al., "High insulin levels in newly diagnosed breast cancer patients reflect underlying insulin resistance and are associated with components of the insulin resistance syndrome," Breast Cancer Research and Treatment, vol. 114, no. 3, pp. 517-525, 2009.

[97] P. J. Goodwin, M. Ennis, K. I. Pritchard et al., "Fasting insulin and outcome in early-stage breast cancer: results of a prospective cohort study," Journal of Clinical Oncology, vol. 20, no. 1, pp. 42-51, 2002.

[98] G. G. Kolden, T. J. Strauman, A. Ward et al., "A pilot study of group exercise training (GET) for women with primary breast cancer: feasibility and health benefits," Psycho-Oncology, vol. 11, no. 5, pp. 447-456, 2002.

[99] C. M. Schneider, C. C. Hsieh, L. K. Sprod, S. D. Carter, and R. Hayward, "Effects of supervised exercise training on cardiopulmonary function and fatigue in breast cancer survivors during and after treatment," Cancer, vol. 110, no. 4, pp. 918-925, 2007.

[100] C.-J. Kim, D.-H. Kang, B. A. Smith, and K. A. Landers, "Cardiopulmonary responses and adherence to exercise in women newly diagnosed with breast cancer undergoing adjuvant therapy," Cancer Nursing, vol. 29, no. 2, pp. 156-165, 2006.

[101] C. C. Hsieh, L. K. Sprod, D. S. Hydock, S. D. Carter, R. Hayward, and C. M. Schneider, "Effects of a supervised exercise intervention on recovery from treatment regimens in breast cancer survivors," Oncology Nursing Forum, vol. 35, no. 6, pp. 909-915, 2008.

[102] A. S. Fairey, K. S. Courneya, C. J. Field et al., "Effect of exercise training on C-reactive protein in postmenopausal breast cancer survivors: a randomized controlled trial," Brain, Behavior, and Immunity, vol. 19, no. 5, pp. 381-388, 2005.

[103] B. M. Pinto, M. M. Clark, N. C. Maruyama, and S. I. Feder, "Psychological and fitness changes associated with exercise participation among women with breast cancer," Psycho-Oncology, vol. 12, no. 2, pp. 118-126, 2003.

[104] E. Guinan, J. Hussey, J. M. Broderick et al., "The effect of aerobic exercise on metabolic and inflammatory markers in breast cancer survivors: a pilot study," Supportive Care in Cancer, vol. 21, no. 7, pp. 1983-1992, 2013.

[105] R. Nuri, M. R. Kordi, M. Moghaddasi et al., "Effect of combination exercise training on metabolic syndrome parameters in postmenopausal women with breast cancer," Journal of Cancer Research and Therapeutics, vol. 8, no. 2, pp. 238-242, 2012.

[106] K. L. Campbell, C. L. Van Patten, S. E. Neil et al., "Feasibility of a lifestyle intervention on body weight and serum biomarkers in breast cancer survivors with overweight and obesity," Journal of the Academy of Nutrition and Dietetics, vol. 112, no. 4, pp. 559$567,2012$.

[107] W. Demark-Wahnefried, L. D. Case, K. Blackwell et al., "Results of a diet/exercise feasibility trial to prevent adverse body composition change in breast cancer patients on adjuvant chemotherapy," Clinical Breast Cancer, vol. 8, no. 1, pp. 70-79, 2008.

[108] M. G. MacVicar, M. L. Winningham, and J. L. Nickel, "Effects of aerobic interval training on cancer patients' functional capacity," Nursing Research, vol. 38, no. 6, pp. 348-351, 1989.

[109] J. S. Drouin, T. J. Young, J. Beeler et al., "Random control clinical trial on the effects of aerobic exercise training on erythrocyte levels during radiation treatment for breast cancer," Cancer, vol. 107, no. 10, pp. 2490-2495, 2006.

[110] K. S. Courneya, J. R. Mackey, G. J. Bell, L. W. Jones, C. J. Field, and A. S. Fairey, "Randomized controlled trial of exercise training in postmenopausal breast cancer survivors: cardiopulmonary and quality of life outcomes," Journal of Clinical Oncology, vol. 21, no. 9, pp. 1660-1668, 2003. 
[111] F. Herrero, A. F. San Juan, S. J. Fleck et al., "Combined aerobic and resistance training in breast cancer survivors: a randomized, controlled pilot trial," International Journal of Sports Medicine, vol. 27, no. 7, pp. 573-580, 2006.

[112] A. S. Fairey, K. S. Courneya, C. J. Field, G. J. Bell, L. W. Jones, and J. R. Mackey, "Effects of exercise training on fasting insulin, insulin resistance, insulin-like growth factors, and insulin-like growth factor binding proteins in postmenopausal breast cancer survivors: a randomized controlled trial," Cancer Epidemiology, Biomarkers \& Prevention, vol. 12, no. 8, pp. 721-727, 2003.

[113] J. A. Ligibel, N. Campbell, A. Partridge et al., "Impact of a mixed strength and endurance exercise intervention on insulin levels in breast cancer survivors," Journal of Clinical Oncology, vol. 26, no. 6, pp. 907-912, 2008.

[114] M. L. Irwin, K. Varma, M. Alvarez-Reeves et al., "Randomized controlled trial of aerobic exercise on insulin and insulin-like growth factors in breast cancer survivors: the yale exercise and survivorship study," Cancer Epidemiology Biomarkers and Prevention, vol. 18, no. 1, pp. 306-313, 2009.

[115] S. N. Blair, H. W. Kohl III, C. E. Barlow, R. S. Paffenbarger Jr., L. W. Gibbons, and C. A. Macera, "Changes in physical fitness and all-cause mortality: a prospective study of healthy and unhealthy men," Journal of the American Medical Association, vol. 273, no. 14, pp. 1093-1098, 1995.

[116] J. Stamler, R. Stamler, and J. D. Neaton, "Blood pressure, systolic and diastolic, and cardiovascular risks: US population data," Archives of Internal Medicine, vol. 153, no. 5, pp. 598-615, 1993.

[117] J. Stamler, G. Rose, R. Stamler, P. Elliott, A. Dyer, and M. Marmot, "INTERSALT study findings. Public health and medical care implications," Hypertension, vol. 14, no. 5, pp. 570-577, 1989.

[118] P. Thavendiranathan, A. D. Grant, T. Negishi, J. C. Plana, Z. B. Popović, and T. H. Marwick, "Reproducibility of echocardiographic techniques for sequential assessment of left ventricular ejection fraction and volumes: application to patients undergoing cancer chemotherapy," Journal of the American College of Cardiology, vol. 61, no. 1, pp. 77-84, 2013.

[119] P. Thavendiranathan, F. Poulin, K.-D. Lim, J. C. Plana, A. Woo, and T. H. Marwick, "Use of myocardial strain imaging by echocardiography for the early detection of cardiotoxicity in patients during and after cancer chemotherap: a systematic review," Journal of the American College of Cardiology, vol. 63, no. 25, pp. 2751-2768, 2014.

[120] A. L. Baggish, K. Yared, F. Wang et al., "The impact of endurance exercise training on left ventricular systolic mechanics," American Journal of Physiology-Heart and Circulatory Physiology, vol. 295, no. 3, pp. H1109-H1116, 2008.

[121] R. A. Argyle and S. G. Ray, "Stress and strain: double trouble or useful tool?" European Journal of Echocardiography, vol. 10, no. 6, pp. 716-722, 2009.

[122] N. Fallah-Rad, J. R. Walker, A. Wassef et al., "The utility of cardiac biomarkers, tissue velocity and strain imaging, and cardiac magnetic resonance imaging in predicting early left ventricular dysfunction in patients with human epidermal growth factor receptor II-positive breast cancer treated with adjuvant trastuzumab therapy," Journal of the American College of Cardiology, vol. 57, no. 22, pp. 2263-2270, 2011.

[123] G.-Y. Cho, T. H. Marwick, H.-S. Kim, M.-K. Kim, K.-S. Hong, and D.-J. Oh, "Global 2-dimensional strain as a new prognosticator in patients with heart failure," Journal of the American College of Cardiology, vol. 54, no. 7, pp. 618-624, 2009.

[124] M. Bertini, A. C. T. Ng, M. L. Antoni et al., "Global longitudinal strain predicts long-term survival in patients with chronic ischemic cardiomyopathy," Circulation: Cardiovascular Imaging, vol. 5, no. 3, pp. 383-391, 2012.

[125] M. Iacoviello, A. Puzzovivo, P. Guida et al., "Independent role of left ventricular global longitudinal strain in predicting prognosis of chronic heart failure patients," Echocardiography, vol. 30, no. 7, pp. 803-811, 2013.

[126] T. Stanton, R. Leano, and T. H. Marwick, "Prediction of all-cause mortality from global longitudinal speckle strain: comparison with ejection fraction and wall motion scoring," Circulation: Cardiovascular Imaging, vol. 2, no. 5, pp. 356-364, 2009.

[127] J. Lekakis, P. Abraham, A. Balbarini et al., "Methods for evaluating endothelial function: a position statement from the European Society of Cardiology Working Group on Peripheral Circulation," European Journal of Cardiovascular Prevention and Rehabilitation, vol. 18, no. 6, pp. 775-789, 2011.

[128] A. Dolci, R. Dominici, D. Cardinale, M. T. Sandri, and M. Panteghini, "Biochemical markers for prediction of chemotherapyinduced cardiotoxicity systematic review of the literature and recommendations for use," The American Journal of Clinical Pathology, vol. 130, no. 5, pp. 688-695, 2008.

[129] F. J. F. Broeyer, S. Osanto, H. J. Ritsema Van Eck et al., "Evaluation of biomarkers for cardiotoxicity of anthracyclin-based chemotherapy," Journal of Cancer Research and Clinical Oncology, vol. 134, no. 9, pp. 961-968, 2008.

[130] S. Romano, S. Fratini, E. Ricevuto et al., "Serial measurements of NT-proBNP are predictive of not-high-dose anthracycline cardiotoxicity in breast cancer patients," British Journal of Cancer, vol. 105, no. 11, pp. 1663-1668, 2011.

[131] M. T. Sandri, M. Salvatici, D. Cardinale et al., "N-terminal pro-B-type natriuretic peptide after high-dose chemotherapy: a marker predictive of cardiac dysfunction?" Clinical Chemistry, vol. 51, no. 8, pp. 1405-1410, 2005.

[132] A. Kittiwarawut, Y. Vorasettakarnkij, S. Tanasanvimon, S. Manasnayakorn, and V. Sriuranpong, "Serum NT-proBNP in the early detection of doxorubicin-induced cardiac dysfunction," Asia-Pacific Journal of Clinical Oncology, vol. 9, no. 2, pp. 155$161,2013$.

[133] H. Sawaya, I. A. Sebag, J. C. Plana et al., "Assessment of echocardiography and biomarkers for the extended prediction of cardiotoxicity in patients treated with anthracyclines, taxanes, and trastuzumab," Circulation: Cardiovascular Imaging, vol. 5, no. 5, pp. 596-603, 2012.

[134] H. Sawaya, I. A. Sebag, J. C. Plana et al., "Early detection and prediction of cardiotoxicity in chemotherapy-treated patients," The American Journal of Cardiology, vol. 107, no. 9, pp. 13751380, 2011.

[135] B. Ky, M. Putt, H. Sawaya et al., "Early increases in multiple biomarkers predict subsequent cardiotoxicity in patients with breast cancer treated with doxorubicin, taxanes, and trastuzumab," Journal of the American College of Cardiology, vol. 63, no. 8, pp. 809-816, 2014.

[136] H. W. Auner, C. Tinchon, W. Linkesch et al., "Prolonged monitoring of troponin $\mathrm{T}$ for the detection of anthracycline cardiotoxicity in adults with hematological malignancies," Annals of Hematology, vol. 82, no. 4, pp. 218-222, 2003.

[137] F. Dodos, T. Halbsguth, E. Erdmann, and U. C. Hoppe, "Usefulness of myocardial performance index and biochemical markers for early detection of anthracycline-induced cardiotoxicity in adults," Clinical Research in Cardiology, vol. 97, no. 5, pp. 318326, 2008.

[138] C. Nisticò, E. Bria, F. Cuppone et al., "Troponin-T and myoglobin plus echocardiographic evaluation for monitoring early 
cardiotoxicity of weekly epirubicin-paclitaxel in metastatic breast cancer patients," Anti-Cancer Drugs, vol. 18, no. 2, pp. 227-232, 2007.

[139] D. Cardinale, M. T. Sandri, A. Martinoni et al., "Myocardial injury revealed by plasma troponin I in breast cancer treated with high-dose chemotherapy," Annals of Oncology, vol. 13, no. 5, pp. 710-715, 2002.

[140] D. Cardinale, M. T. Sandri, A. Colombo et al., "Prognostic value of troponin I in cardiac risk stratification of cancer patients undergoing high-dose chemotherapy," Circulation, vol. 109, no. 22, pp. 2749-2754, 2004.

[141] M. T. Sandri, D. Cardinale, L. Zorzino et al., "Minor increases in plasma troponin I predict decreased left ventricular ejection fraction after high-dose chemotherapy," Clinical Chemistry, vol. 49, no. 2, pp. 248-252, 2003.

[142] M. Feola, O. Garrone, M. Occelli et al., "Cardiotoxicity after anthracycline chemotherapy in breast carcinoma: effects on left ventricular ejection fraction, troponin I and brain natriuretic peptide," International Journal of Cardiology, vol. 148, no. 2, pp. 194-198, 2011.

[143] B. C. Drafts, K. M. Twomley, R. D’Agostino Jr. et al., "Low to moderate dose anthracycline-based chemotherapy is associated with early noninvasive imaging evidence of subclinical cardiovascular disease," JACC: Cardiovascular Imaging, vol. 6, no. 8, pp. 877-885, 2013.

[144] B. Erkus, S. Demirtas, A. A. Yarpuzlu, M. Can, Y. Genc, and L. Karaca, "Early prediction of anthracycline induced cardiotoxicity," Acta Paediatrica, International Journal of Paediatrics, vol. 96, no. 4, pp. 506-509, 2007.

[145] G. Mercuro, C. Cadeddu, A. Piras et al., "Early epirubicininduced myocardial dysfunction revealed by serial tissue Doppler echocardiography: correlation with inflammatory and oxidative stress markers," Oncologist, vol. 12, no. 9, pp. 1124-1133, 2007.

[146] S. Polena, M. Shikara, S. Naik et al., "Troponin I as a marker of doxorubicin induced cardiotoxicity," Proceedings of the Western Pharmacology Society, vol. 48, pp. 142-144, 2005.

[147] D. Cardinale, A. Colombo, R. Torrisi et al., "Trastuzumab-induced cardiotoxicity: clinical and prognostic implications of troponin I evaluation," Journal of Clinical Oncology, vol. 28, no. 25, pp. 3910-3916, 2010.

[148] T. Ahmad, M. Fiuzat, D. B. Mark et al., "The effects of exercise on cardiovascular biomarkers in patients with chronic heart failure," American Heart Journal, vol. 167, no. 2, pp. 193.e1202.e1, 2014.

[149] O. Schulz and A. Kromer, "Cardiac troponin I: a potential marker of exercise intolerance in patients with moderate heart failure," American Heart Journal, vol. 144, no. 2, pp. 351-358, 2002.

[150] U. Wisløff, Ø. Ellingsen, and O. J. Kemi, "High-intensity interval training to maximize cardiac benefits of exercise training?" Exercise and Sport Sciences Reviews, vol. 37, no. 3, pp. 139-146, 2009.

[151] U. Wisløff, A. Støylen, J. P. Loennechen et al., "Superior cardiovascular effect of aerobic interval training versus moderate continuous training in heart failure patients: a randomized study," Circulation, vol. 115, no. 24, pp. 3086-3094, 2007.

[152] C. A. Emter and D. K. Bowles, "Curing the cure: utilizing exercise to limit cardiotoxicity," Medicine and Science in Sports and Exercise, vol. 40, no. 5, pp. 806-807, 2008.

[153] M. J. Haykowsky, Y. Liang, D. Pechter, L. W. Jones, F. A. McAlister, and A. M. Clark, "A Meta-analysis of the effect of exercise training on left ventricular remodeling in heart failure patients: the benefit depends on the type of training performed," Journal of the American College of Cardiology, vol. 49, no. 24, pp. 2329-2336, 2007.

[154] K. M. Baldwin and F. Haddad, "Invited review: effects of different activity and inactivity paradigms on myosin heavy chain gene expression in striated muscle," Journal of Applied Physiology, vol. 90, no. 1, pp. 345-357, 2001.

[155] E. L. de Beer, A. E. Bottone, J. van der Velden, and E. E. Voest, "Doxorubicin impairs crossbridge turnover kinetics in skinned cardiac trabeculae after acute and chronic treatment," Molecular Pharmacology, vol. 57, no. 6, pp. 1152-1157, 2000.

[156] H.-B. Kwak, W. Song, and J. M. Lawler, "Exercise training attenuates age-induced elevation in $\mathrm{Bax} / \mathrm{Bcl}-2$ ratio, apoptosis, and remodeling in the rat heart," The FASEB Journal, vol. 20, no. 6, pp. 791-793, 2006.

[157] M. Marcil, K. Bourduas, A. Ascah, and Y. Burelle, "Exercise training induces respiratory substrate-specific decrease in $\mathrm{Ca}^{2+}$ induced permeability transition pore opening in heart mitochondria," The American Journal of Physiology-Heart and Circulatory Physiology, vol. 290, no. 4, pp. H1549-H1557, 2006.

[158] D. Montaigne, X. Marechal, S. Preau et al., "Doxorubicin induces mitochondrial permeability transition and contractile dysfunction in the human myocardium," Mitochondrion, vol. 11, no. 1, pp. 22-26, 2011.

[159] V. Adams, A. Linke, S. Gielen, S. Erbs, R. Hambrecht, and G. Schuler, "Modulation of Murf-1 and MAFbx expression in the myocardium by physical exercise training," European Journal of Cardiovascular Prevention and Rehabilitation, vol. 15, no. 3, pp. 293-299, 2008.

[160] Y. Shi, M. Moon, S. Dawood, B. McManus, and P. P. Liu, "Mechanisms and management of doxorubicin cardiotoxicity," Herz, vol. 36, no. 4, pp. 296-305, 2011.

[161] S. Hamed, I. Barshack, G. Luboshits et al., "Erythropoietin improves myocardial performance in doxorubicin-induced cardiomyopathy," European Heart Journal, vol. 27, no. 15, pp. 1876$1883,2006$.

[162] H. A. Demirel, K. L. Hamilton, R. A. Shanely, N. Tümer, M. J. Koroly, and S. K. Powers, "Age and attenuation of exerciseinduced myocardial HSP72 accumulation," American Journal of Physiology: Heart and Circulatory Physiology, vol. 285, no. 4, pp. H1609-H1615, 2003.

[163] T. Ohtsuboa, E. Kanob, K. Uedac et al., "Enhancement of heatinduced heat shock protein (hsp)72 accumulation by doxorubicin (Dox) in vitro," Cancer Letters, vol. 159, no. 1, pp. 49-55, 2000.

[164] O. J. Kemi, M. Ceci, G. Condorelli, G. L. Smith, and U. Wisloff, "Myocardial sarcoplasmic reticulum $\mathrm{Ca}^{2+}$ ATPase function is increased by aerobic interval training," European Journal of Cardiovascular Prevention and Rehabilitation, vol. 15, no. 2, pp. 145-148, 2008.

[165] R. D. Olson, H. A. Gambliel, R. E. Vestal, S. E. Shadle, H. A. Charlier Jr., and B. J. Cusack, "Doxorubicin cardiac dysfunction: effects on calcium regulatory proteins, sarcoplasmic reticulum, and triiodothyronine," Cardiovascular Toxicology, vol. 5, no. 3, pp. 269-283, 2005.

[166] V. W. Dolinsky, K. J. Rogan, M. M. Sung et al., "Both aerobic exercise and resveratrol supplementation attenuate doxorubicin-induced cardiac injury in mice," American Journal of Physiology-Endocrinology and Metabolism, vol. 305, no. 2, pp. E243-E253, 2013. 
[167] P. M. Siu, R. W. Bryner, J. K. Marty, and S. E. Alway, "Apoptotic adaptations from exercise training in skeletal and cardiac muscles," The FASEB Journal, vol. 18, no. 10, pp. 1150-1152, 2004.

[168] S. H. Kim, D. Kim, G. S. Jung, J. H. Um, B. S. Chung, and C. D. Kang, "Involvement of c-Jun $\mathrm{NH}_{2}$-terminal kinase pathway in differential regulation of heat shock proteins by anticancer drugs," Biochemical and Biophysical Research Communications, vol. 262, no. 2, pp. 516-522, 1999.

[169] D. L. Coven, X. Hu, L. Cong et al., "Physiological role of AMPactivated protein kinase in the heart: graded activation during exercise," American Journal of Physiology - Endocrinology and Metabolism, vol. 285, no. 3, pp. E629-E636, 2003.

[170] M. Tokarska-Schlattner, M. Zaugg, R. da Silva et al., "Acute toxicity of doxorubicin on isolated perfused heart: response of kinases regulating energy supply," American Journal of Physiology-Heart and Circulatory Physiology, vol. 289, no. 1, pp. H37-H47, 2005.

[171] P. Boström, N. Mann, J. Wu et al., "C/EBP $\beta$ controls exerciseinduced cardiac growth and protects against pathological cardiac remodeling," Cell, vol. 143, no. 7, pp. 1072-1083, 2010.

[172] A. de Angelis, E. Piegari, D. Cappetta et al., "Anthracycline cardiomyopathy is mediated by depletion of the cardiac stem cell pool and is rescued by restoration of progenitor cell function," Circulation, vol. 121, no. 2, pp. 276-292, 2010.

[173] Y. Yang, H. Zhang, X. Li, T. Yang, and Q. Jiang, "Effects of PPAR $\alpha /$ PGC- $1 \alpha$ on the myocardial energy metabolism during heart failure in the doxorubicin induced dilated cardiomyopathy in mice," International Journal of Clinical and Experimental Medicine, vol. 7, pp. 2435-2442, 2014.

[174] D. B. Sawyer, C. Zuppinger, T. A. Miller, H. M. Eppenberger, and T. M. Suter, "Modulation of anthracycline-induced myofibrillar disarray in rat ventricular myocytes by neuregulin- $1 \beta$ and anti-erbB2: potential mechanism for trastuzumab-induced cardiotoxicity," Circulation, vol. 105, no. 13, pp. 1551-1554, 2002.

[175] Y. Kim, A.-G. Ma, K. Kitta et al., "Anthracycline-induced suppression of GATA-4 transcription factor: implication in the regulation of cardiac myocyte apoptosis," Molecular Pharmacology, vol. 63, no. 2, pp. 368-377, 2003. 


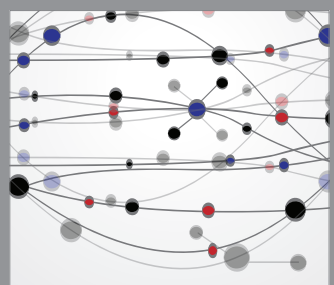

The Scientific World Journal
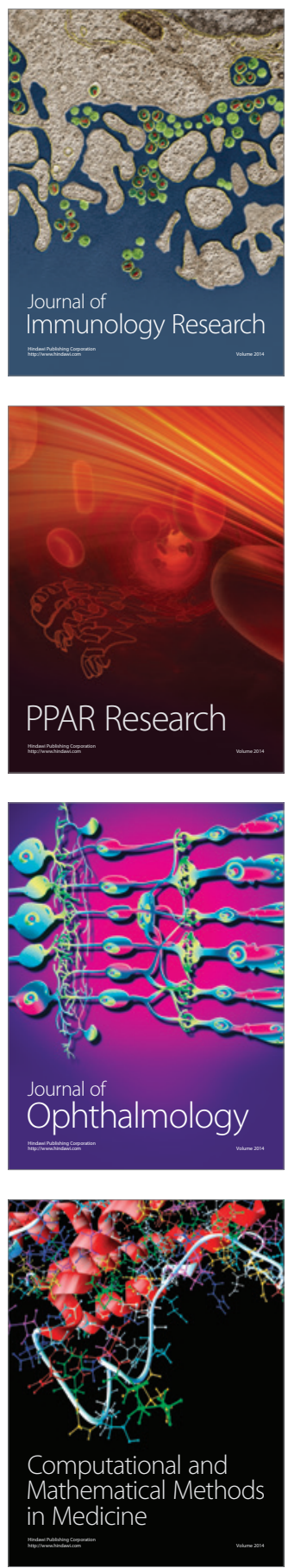

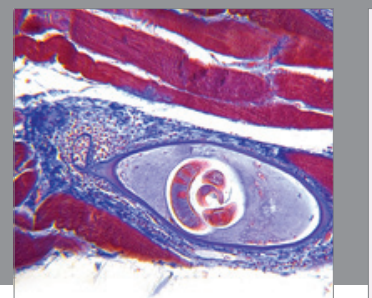

Gastroenterology

Research and Practice
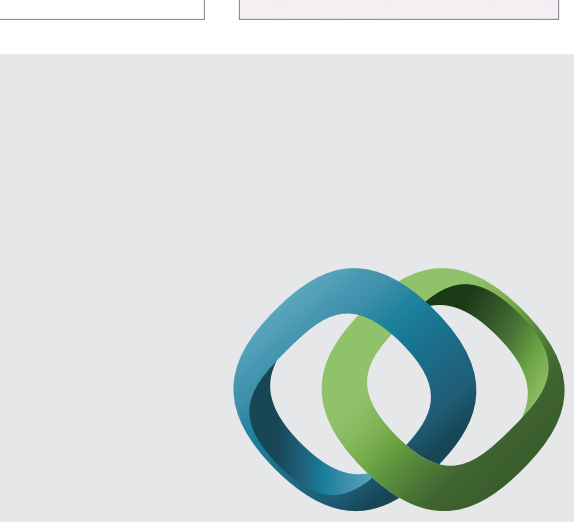

\section{Hindawi}

Submit your manuscripts at

http://www.hindawi.com
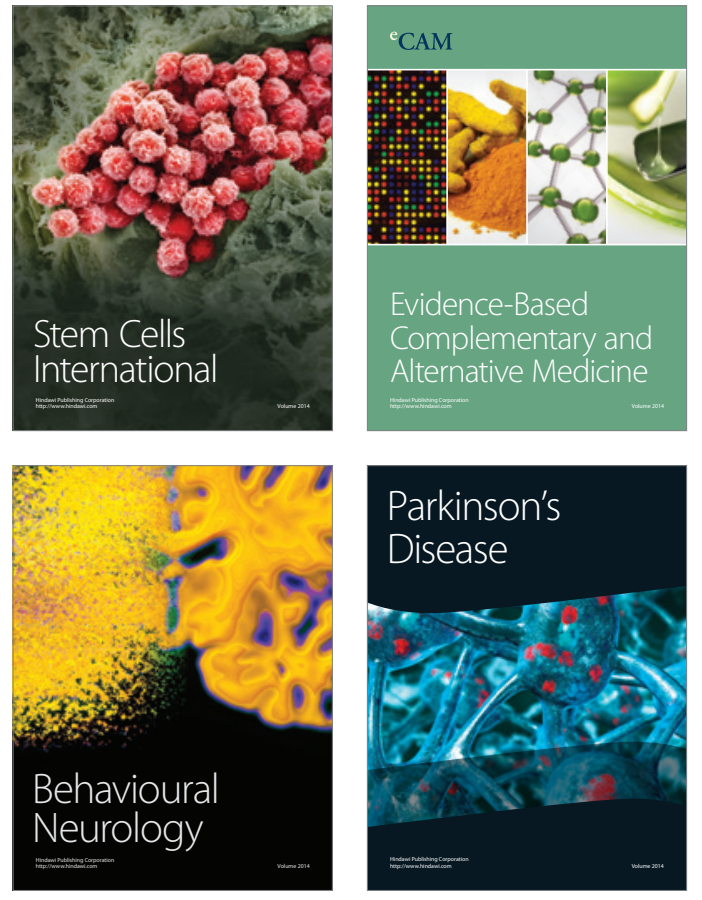
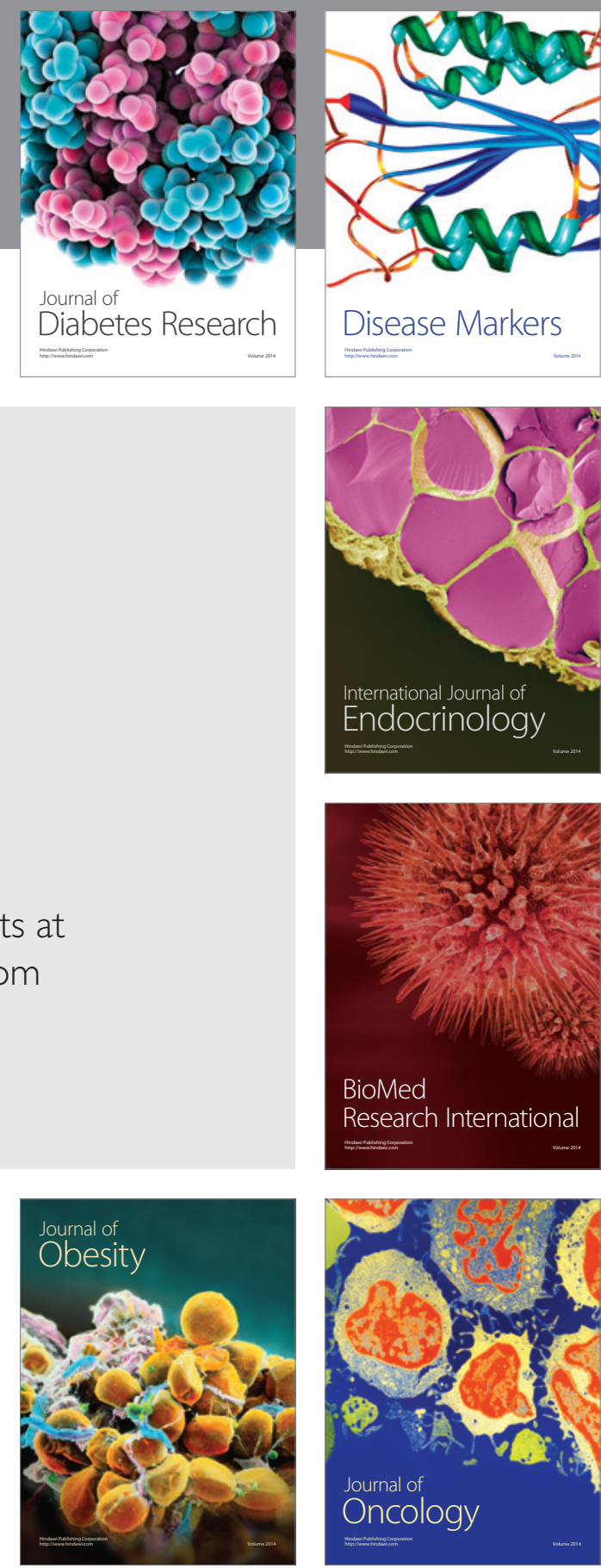

Disease Markers
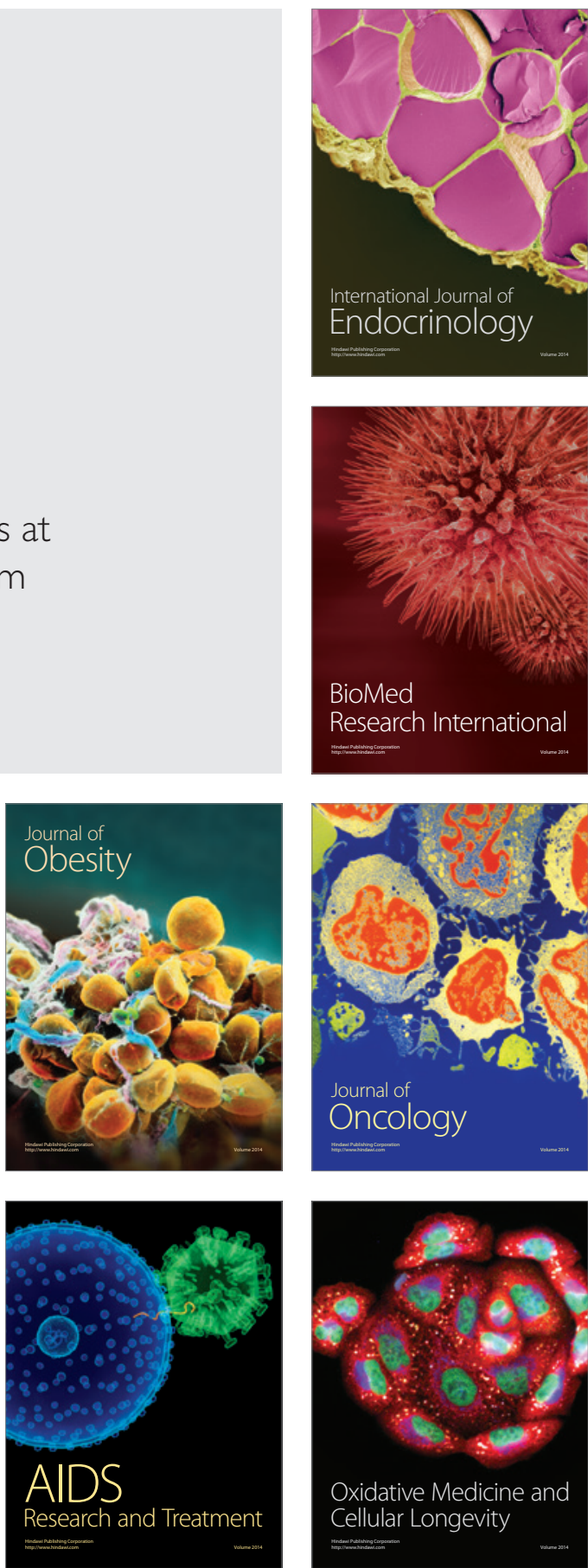